The Journal of Laryngology \& Otology

http://journals.cambridge.org/JLO

Additional services for The Journal of Laryngology \& Otology:

Email alerts: $\underline{\text { Click here }}$

Subscriptions: $\underline{\text { Click here }}$

Commercial reprints: Click here

Terms of use : $\underline{\text { Click here }}$

\title{
Maxillary sinus haematoma
}

M Lim, S Lew-Gor, T Beale, A Ramsay and V J Lund

The Journal of Laryngology \& Otology / Volume 122 / Issue 02 / February 2008, pp 210 - 212

DOI: 10.1017/S0022215107007219, Published online: 16 April 2007

Link to this article: http://journals.cambridge.org/abstract_S0022215107007219

How to cite this article:

M Lim, S Lew-Gor, T Beale, A Ramsay and V J Lund (2008). Maxillary sinus haematoma. The Journal of Laryngology \& Otology, 122, pp 210-212 doi:10.1017/S0022215107007219

Request Permissions : $\underline{\text { Click here }}$ 


\title{
Maxillary sinus haematoma
}

\author{
M Lim, S Lew-Gor, T BeAle*, A Ramsay $\dagger$, V J Lund
}

\begin{abstract}
The maxillary sinus haematoma is an uncommon cause of a maxillary sinus mass. It presents with a variety of symptoms, the most common being epistaxis. Although histologically benign, it may be clinically progressive. Radiological findings can range from a benign appearance to a more aggressive process, including bony erosion. Surgical evacuation is the mainstay of therapy. We describe our experience in managing this condition and review available literature on the subject.
\end{abstract}

Key words: Maxillary Sinus; Haematoma; Endoscopy

\section{Introduction}

The constellation of symptoms of nasal obstruction, facial swelling, proptosis, epistaxis, and facial numbness or paraesthesia - is likely to be associated with significant sinonasal pathology, and poses a diagnostic dilemma for the attending clinician. Benign conditions to consider include fungal infection, inverted papilloma, antrochoanal polyp, mucocele, cholesterol granuloma and osseous lesions. Included in the differential diagnosis are a wide variety of malignant tumours of the sinonasal cavity, of which the majority are squamous cell carcinomas.

It can be difficult to come to a diagnosis based on clinical presentation and examination alone. Computerised tomography (CT) and magnetic resonance imaging (MRI) are useful in suggesting a malignant or benign aetiology, but the final diagnosis requires histological evaluation.

The maxillary sinus haematoma is a rare condition. However, its clinical significance lies in the fact that, although histologically benign, it may be clinically progressive.

We describe our experience in the management of this condition and review the literature on this subject.

\section{Case study}

A 56-year-old woman presented with a six-month history of right-sided nasal blockage, swelling of the right side of the face and blood-stained nasal discharge.

Examination revealed right eye proptosis, with bulging of the right lateral nasal wall on endoscopy.

A CT scan showed an expanded, homogeneously opaque right maxilla, with elevation of the floor of the orbit and expansion of the medial wall into the nasal cavity (Figure 1). The differential diagnosis, based on radiological appearances alone, included an antral mucocele and a slow-growing, benign tumour.

Endoscopic sinus surgery was performed, during which a haemorrhagic mass was found filling the maxillary sinus, with no obvious point of origin. A large middle meatal antrostomy was fashioned, including the middle third of the inferior turbinate. The mass was removed completely, leaving the mucosa intact.

Histology showed the mass to consist of fibrin and red cells making up a blood clot. Focal areas of dystrophic calcification were present, suggesting chronicity. Fungal staining was negative and there was no evidence of a neoplasm (Figure 2).

Further questioning did not reveal any history of a bleeding disorder or previous trauma. Subsequent follow up at six months showed a well healed, empty maxillary sinus via a patent middle meatal antrostomy.

\section{Discussion}

Maxillary sinus haematoma, also known as organised haematoma or haemorrhagic pseudotumour, is a rare entity. It may occur on a background of bleeding diathesis, such as Von Willebrand's disease and clotting factor deficiency. ${ }^{1,2}$ Spontaneous cases are rare, with only 11 reported in the English literature.

The pathogenesis in spontaneous cases is unclear. Possible causes include leakage of blood from the nasal passage into the maxillary ostium or rupture of arteries and aneurysms supplying the maxillary sinus. ${ }^{3}$ Accumulation of blood at a rate that exceeds mucociliary clearance by the sinus results in formation of the haematoma. ${ }^{4}$

A maxillary sinus haematoma presents clinically like any maxillary mass. It is typically locally expansive, compressing adjacent structures and sometimes eroding bone. The reason for its progressive nature is thought to relate to formation of a fibrous capsule around the blood clot, which prevents reabsorption of the haematoma. Further bleeding results in increasing pressure within the haematoma, and it expands to compress or erode neighbouring structures. ${ }^{1,4}$

We reviewed the literature for all reports of spontaneous cases of maxillary haematoma. Table I illustrates the patient profiles and management for these patients. There were 12 patients in total, including our case. Patients' ages ranged from 18 to 78 years. Epistaxis seemed to be a universal symptom amongst these patients, with unilateral 


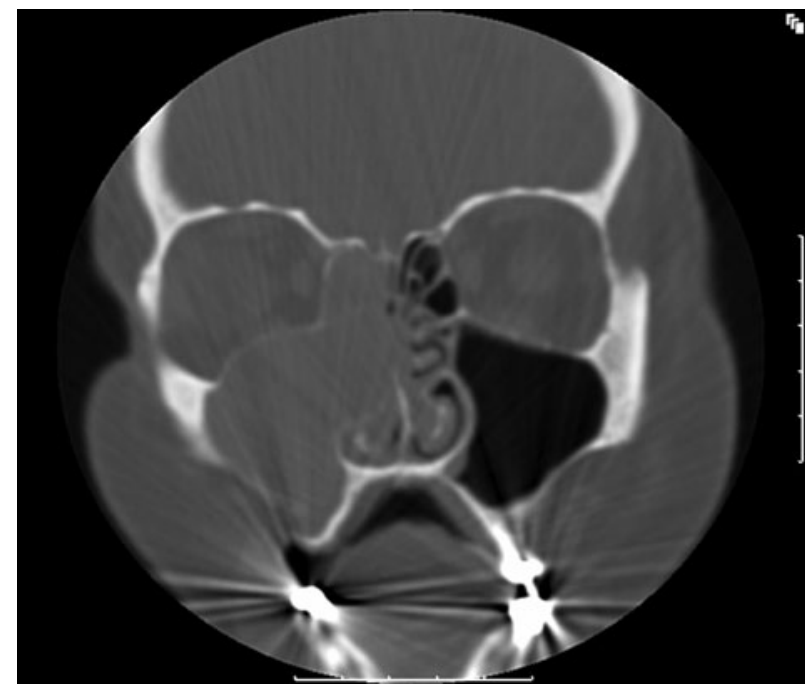

FIG. 1

Coronal computed tomography scan showing homogeneous right maxilla with elevation of orbital floor.

nasal obstruction and facial swelling also being common. Typical examination findings were medialisation of the lateral nasal wall, with or without the presence of a mass visible at the middle meatus.

The investigation of choice for a sinonasal mass is a combination of CT and MRI. Magnetic resonance alone offers better differentiation of the tumour from surrounding tissue and fluid, but coronal CT allows demonstration of bony erosion. ${ }^{5}$ On CT, a maxillary haematoma appears as a non-enhancing, soft tissue mass, which may be heterogenous or homogeneous. The mass is non-enhancing on both T1 and T2 MRI sequences. ${ }^{4,6}$ Heterogeneous signal intensity on MRI represents different phases of blood products caused by rebleeding into the sinus. ${ }^{1}$

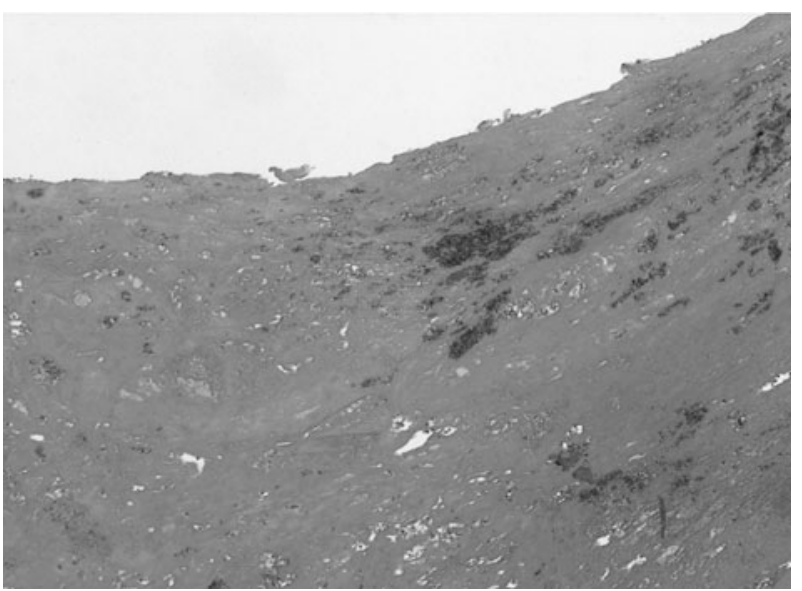

FIG. 2

Low power photomicrograph of sinus contents from case one, showing a solid mass of fibrin with entrapped red and white blood cells $(H \& E$; original magnification $\times 25)$.

Six of the reviewed cases had bony erosion, although the term 'bony erosion' is sometimes used interchangeably with 'simple thinning' of the bony walls. Nonetheless, there were definitely at least two cases in which the inferior wall of the orbit was completely destroyed. ${ }^{4,6}$ It can be difficult to make the diagnosis of maxillary haematoma based on imaging alone, as the appearance may range from a benign process, such as a mucocele or a slow-growing tumour (as in our case), to a more aggressive process. ${ }^{4,6}$ However, the radiological findings are important in order to determine pre-operatively the extent of the mass and the anatomical areas it has invaded.

Histologically, the organised haematoma consists of a central, amorphous, eosinophilic, relatively acellular fibrinous mass with some intact erythrocytes within it.

TABLE I

SPONTANEOUS MAXILLARY HAEMATOMA IN LITERATURE

\begin{tabular}{|c|c|c|c|c|c|c|}
\hline Pt. & Author & Age & Sex & Presentation & Radiological Findings & Management \\
\hline 1 & Unlu, 2000 & 42 & $\mathrm{M}$ & $\begin{array}{l}\text { Swelling left cheek, } \\
\text { pain, nasal } \\
\text { obstruction, epistaxis }\end{array}$ & $\begin{array}{l}\text { CT - soft tissue mass, } \\
\text { nonenhancing, bony destruction } \\
\text { superior medial wall of sinus }\end{array}$ & Lateral rhinotomy \\
\hline 2 & Unlu, 2000 & 78 & $\mathrm{~F}$ & Epistaxis only & $\begin{array}{l}\mathrm{CT} \text { - soft tissue mass, bony } \\
\text { destruction medial wall of sinus }\end{array}$ & Lateral rhinotomy \\
\hline 3 & $\begin{array}{l}\text { Tabaee, } \\
2002\end{array}$ & 18 & $\mathrm{M}$ & $\begin{array}{l}\text { Facial numbness, } \\
\text { left upper dental } \\
\text { pain, retro-orbital pain }\end{array}$ & $\begin{array}{l}\mathrm{CT} \text { - soft tissue mass, } \\
\text { nonenhancing, erosion of } \\
\text { left orbital floor }\end{array}$ & $\begin{array}{l}\text { Combined Endoscopic } \\
\text { and Caldwell-Luc }\end{array}$ \\
\hline 4 & Lee, 2003 & 18 & $\mathrm{M}$ & Epistaxis* & No bony erosion & Endoscopic Sinus Surgery \\
\hline 5 & Lee, 2003 & 32 & $\mathrm{M}$ & Epistaxis* & No bony erosion & Denker's Operation \\
\hline 6 & Lee, 2003 & 51 & $\mathrm{~F}$ & Epistaxis* & No bony erosion & Endoscopic Sinus Surgery \\
\hline 7 & Lee, 2003 & 52 & $\mathrm{M}$ & Epistaxis* & No bony erosion & $\begin{array}{l}\text { Combined Endoscopic } \\
\text { and Caldwell-Luc }\end{array}$ \\
\hline 8 & Lee, 2003 & 55 & $\mathrm{M}$ & Epistaxis* & Bony erosion & $\begin{array}{l}\text { Combined Endoscopic } \\
\text { and Caldwell-Luc }\end{array}$ \\
\hline 9 & Lee, 2003 & 67 & $\mathrm{M}$ & Epistaxis* & Bony erosion & $\begin{array}{l}\text { Combined Endoscopic } \\
\text { and Caldwell-Luc }\end{array}$ \\
\hline 10 & Lee, 2003 & 67 & $\mathrm{M}$ & Epistaxis* & No bony erosion & $\begin{array}{l}\text { Combined Endoscopic } \\
\text { and Caldwell-Luc }\end{array}$ \\
\hline 11 & Lee, 2003 & 67 & $\mathrm{~F}$ & Epistaxis* & Bony erosion & $\begin{array}{l}\text { Combined Endoscopic } \\
\text { and Caldwell-Luc }\end{array}$ \\
\hline 12 & $\begin{array}{l}\text { Our Case, } \\
2006\end{array}$ & 56 & $\mathrm{~F}$ & $\begin{array}{l}\text { Right sided nasal } \\
\text { obstruction \& swelling } \\
\text { of face, epistaxis }\end{array}$ & $\begin{array}{l}\text { No bony erosion, but secondary } \\
\text { elevation of orbital floor } \\
\text { and medial expansion }\end{array}$ & Endoscopic Sinus Surgery \\
\hline
\end{tabular}

*Other presentations collectively reported as unilateral nasal obstruction, hyposmia, headache and swollen cheeks 
Peripherally, it has a fibrous capsule with spindle-shaped myo-fibroblast cells. ${ }^{4}$

Due to its progressive nature, the mass cannot be treated conservatively. Local irradiation has been used as a treatment modality at other body sites, although this is clearly inappropriate at the maxillary sinus. ${ }^{1}$ Surgical evacuation is the mainstay of treatment. In the majority of the cases in the literature, the attending surgeon employed an external approach or a combined endoscopic and external approach. The external approaches used included the lateral rhinotomy and the less invasive Caldwell-Luc. These approaches were used to gain sufficient surgical exposure, due to concern over the possibility of a malignant process in many of the cases.

Technically, we found it possible to remove the organised haematoma in its entirety by an endoscopic approach alone, via a large middle meatal antrostomy. Adequate access to the floor of the maxillary sinus may be obtained by removal of the middle third of the inferior turbinate.

- Maxillary sinus haematoma is a histologically benign condition but may present in a progressive fashion

- Epistaxis is the most common presenting symptom

- Histologically, the organised haematoma consists of a central, amorphous, eosinophilic, relatively acellular, fibrinous mass with some intact erythrocytes within it

- An endoscopic approach might be attempted in the first instance both to establish the diagnosis and to effect a cure
Ultimately, the approach employed depends on the surgeon's experience. However, we would recommend that, if maxillary sinus haematoma is suspected (e.g. in the case of a history of bleeding diathesis), an endoscopic approach might be attempted in the first instance both to establish the diagnosis and to effect a cure.

\section{References}

1 Ozhan S, Arac M, Isik S, Oznur II, Atilla S, Kemaloglu Y. Pseudotumor of the maxillary sinus in a patient with von Willebrand's disease. AJR Am J Roentgenol 1996;166:950-1

2 Lee PK, Wu JK, Ludemann JP. Haemorrhagic pseudotumour of the maxillary sinus. J Otolaryngol 2004;33:206-8

3 Unlu HH, Mutlu C, Ayhan S, Tarhan S. Organized haematoma of the maxillary sinus mimicking tumour. Auris Nasus Larynx 2001;28:253-5

4 Tabaee A, Kacker A. Haematoma of the maxillary sinus presenting as a mass - a case report and review of literature. Int J Pediatr Otorhinolaryngol 2002;65:153-7

5 Lloyd G, Lund VJ, Howard D, Savy L. Optimum imaging for sinonasal malignancy. J Laryngol Otol 2000;114:557-62

6 Lee BJ, Park HJ, Heo SC. Organized hematoma of the maxillary sinus. Acta Otolaryngol 2003;123:869-72

Address for correspondence:

VJ Lund,

Royal National Throat, Nose and Ear Hospital,

330-336 Grays Inn Rd,

London WC1X 8EE, UK.

E-mail: v.lund@ucl.ac.uk

Mr Mingyann Lim takes responsibility for the integrity of the content of the paper.

Competing interests: None declared 